\title{
The Effect of Tumor Sideness and Mutational Status on First Line Treatment Response and Survival in The Patients with Metastatic Colorectal Cancer
}

\author{
Kadir ESER ${ }^{1}$, Emel SEZER ${ }^{2}$, Banu OZTURK ${ }^{3}$, Arif Hakan ONDER ${ }^{3}$, Vehbi ERCOLAK ${ }^{2}$, \\ Zeynep ORUC ${ }^{4}$, Ali INAL ${ }^{1}$
}

\author{
${ }^{1}$ Mersin Training and Research Hospital Department of Medical Oncology, Mersin \\ ${ }^{2}$ Mersin University, Faculty of Medicine, Department of Medical Oncology, Mersin \\ ${ }^{3}$ Antalya Education and Research Hospital, Department of Medical Oncology, Antalya \\ ${ }^{4}$ Dicle University Faculty of Medicine Department of Medical Oncology, Diyarbakir, TURKEY
}

\begin{abstract}
RAS and BRAF mutation and primary tumour sideness are prognostic and predictive factors in metastatic colorectal cancer (mCRC). We aimed to investigate RAS-BRAF mutation rates and responses to biologic agents the effects of tumour sideness on survival. This was a retrospective study conducted at three Turkish institutes. 303 patients with mCRC who were examined for tumour RAS and 172 examined for tumour BRAF mutations between 2006-2018. A total of 303 (M/F=186/117) patients were included to study. Median age was 63 (range: 23-86) years. Median follow-up was 22.8 (range: 19.1-26.4) months. In the RAS wild type population; addition to anti-EGFR agents to standard chemotherapy (CT) had better outcomes than Bevacizumab+CT. Median PFS was improved with anti-EGFR agents (Respectively PFS; 14.5 months, 8.7 months) (log rank $p=0.007 \mathrm{HR}=0.59$ ). Median OS was similar between CT+anti-EGFR and CT+Bevacizumab arms (Respectively OS; 29.3 months, 21.7 months) (log rank p= 0.418; HR= 0.75). RAS mutation rates were similar between right colon cancer $(\mathrm{RCC})$ and left colon cancer (LCC), BRAF mutation rates were significantly increased in RCC (22.2 vs 2.7\%, p< 0.0001). RCC (24.1\%) had worse prognosis than LCC (75.9\%). However, this difference was not significant (PFS: 10.4 vs 10.0 months (log rank $p=0.136)$, OS: 21.5 vs 23.1 months (log rank $p=0.436$ ). We concluded that in the patients with RAS wild type tumours, CT and anti-EGFR combination was reasonable approach for first line treatment. BRAF mutation, irrespective of CT regimen, was associated with poor survival and more common in RCC patients.
\end{abstract}

Keywords: Metastatic colorectal cancer, RAS and BRAF, Sidedness, Prognosis

\section{INTRODUCTION}

In metastatic colorectal cancer (mCRC), median overall survival (OS) of 30 months has been reached in clinical trials investigating the RAS wild-type population. ${ }^{1-3}$ The EGFR signalling pathway has a key role in the proliferation and survival of colorectal cancer cells. All ras mutations were associated with responsiveness to anti-EGFR treatment. ${ }^{4}$ While meaningful progress has been achieved for RAS-wild population, outcome of patients with RAS- or BRAF mutant tumours remains poor. In the era of biological targeted agents such as antiVEGF (Bevacizumab) or anti-EGFR (Cetuximab or Panitumumab), the choice of biological agent was investigated in several studies. Two phase III studies addressed the question whether VEGF-A or EGFR blockade should be applied in the first-line treatment of mCRC of KRAS exon 2 wild-type tumours. ${ }^{1,3}$ In addition to RAS, BRAF mutations are potential biomarkers of response to anti-EGFR targeted therapies. ${ }^{5}$ Retrospective analyses for both the FIRE-3 and the CALGB 80405 trial analysed the extended RAS wild-type population, excluding mutations in KRAS and NRAS exon 2, 3 and 4, as the licensed patient population for anti-EGFR mAbs. ${ }^{1}$ 
Analysis of BRAF mutations in mCRC patients has been suggested by the National Comprehensive Cancer Network (NCCN) guidelines for several years ${ }^{6}$ and has recently also been recommended by the European Society of Medical Oncology (ESMO) consensus guideline. ${ }^{7}$ BRAF mutation occurs at a rate of $8-10 \%$ in mCRC patients and is notably associated with a poor prognosis.

We aimed to investigate RAS and BRAF mutation rates and treatment outcomes of first line therapy according to mutation states. Besides to RAS-BRAF mutation status, in our study, primary tumour sidedness of mCRC patients were classified as right and left-sided, prognostic and predictive value of tumour sidedness also evaluated. The prognostic and predictive value of primary tumor sidedness in the patients with mCRC is well known today. Right-sided primary was associated with high mutational burden, microsatellite instability, worse prognosis, more BRAF mutation rates and poor anti-EGFR response. Right-sided primary (those originating in the appendix, cecum, ascending colon, hepatic flexure, or two-thirds of the transverse colon), derived from embryonic midgut tends to more common in men and $\mathrm{CpG}$ island methylator phenotype (CIMP)-high, mutagenic metabolites of cytochrome p450, MAPK signaling and mucinous histology are other molecular characteristics. ${ }^{8-10}$ Contrary, left-sided primary (those originating in the splenic flexure, descending colon, sigmoid colon, rectum, or one-third of the transverse colon), derived from embryonic hindgut, is more common in men, has favorable prognosis and sensitivity of anti-EGFR agents. ${ }^{11,12}$

\section{PATIENTS AND METHOD}

\section{Patients}

This was a retrospective study conducted at three Turkish institutes and approved by the ethics committee of Mersin University Medical School (No 2018/236). Of the 303 consecutive patients with histologically confirmed CRC who were examined for tumor RAS, and 180 examined for tumor BRAF mutations in our institute between November 2006 and December 2018, 177 patients were administered combination chemotherapy with Bevacuzimab as the first-line treatment for $\mathrm{mCRC}$,
111 patients were administered combination chemotherapy with antiEGFR as the first-line treatment for mCRC. Patients who received neo-adjuvant chemotherapy (NAC) or adjuvant chemotherapy completed less than 6 months before enrollment to this study were excluded. Patients who had undergone surgery for metastatic sites were included if it had been performed more than 4 weeks earlier. Patients were required to have adequate hematologic, hepatic, cardiac, and renal function. Their medical records were reviewed to obtain data on clinic-pathologic variables.

\section{Treatment}

The treatment regimen was determined by the physician for each patient. The following regimens were employed: modified FOLFOX6 plus Bevacuzimab (Beva) or anti-EGFR consisted of a fortnightly course of Beva $(5 \mathrm{mg} / \mathrm{kg}$ intravenously over 30 to $90 \mathrm{~min}$ on day 1 ) or anti-EGFR (Cetuximab intravenously loading dose $\left(400 \mathrm{mg} / \mathrm{m}^{2}\right)$ over 2 hours, weekly maintenance dose $(250 \mathrm{mg} /$ $\mathrm{m}^{2}$ ) over 1 hour, Panitumumab intravenously $6 \mathrm{mg} /$ $\mathrm{kg}$ every 14 days), oxaliplatin $\left(85 \mathrm{mg} / \mathrm{m}^{2}\right.$ intravenously over $2 \mathrm{~h}$ on day 1) plus $1-\mathrm{LV}\left(200 \mathrm{mg} / \mathrm{m}^{2}\right.$ intravenously over $2 \mathrm{~h}$ on day 1 ) and 5-fluorouracil (5-FU) $\left(400 \mathrm{mg} / \mathrm{m}^{2}\right.$ bolus on day 1 , followed by infusion of $2400 \mathrm{mg} / \mathrm{m}^{2}$ over $46 \mathrm{~h}$ ); FOLFIRI plus Beva or anti-EGFR consisted of fortnightly courses of Beva $(5 \mathrm{mg} / \mathrm{kg}$ intravenously over 30 to $90 \mathrm{~min}$ on day 1) or anti-EGFR (Cetuximab intravenously loading dose $\left(400 \mathrm{mg} / \mathrm{m}^{2}\right)$ over 2 hours, weekly maintenance dose $\left(250 \mathrm{mg} / \mathrm{m}^{2}\right)$ over 1 hour, Panitumumab intravenously $6 \mathrm{mg} / \mathrm{kg}$ every 14 days), irinotecan $\left(150 \mathrm{mg} / \mathrm{m}^{2}\right.$ intravenously over $2 \mathrm{~h}$ on day 1) plus $1-\mathrm{LV}\left(200 \mathrm{mg} / \mathrm{m}^{2}\right.$ intravenously over $2 \mathrm{~h}$ on day 1$)$ and 5 -FU $\left(400 \mathrm{mg} / \mathrm{m}^{2}\right.$ bolus on day 1 , followed by infusion of $2400 \mathrm{mg} / \mathrm{m}^{2}$ over $46 \mathrm{~h}$ )

\section{Mutational Analysis}

Analysis of RAS and BRAF mutations have been previously described. In brief, molecular analysis was centrally performed by pyrosequencing technique. For RAS mutations exons 2, 3, and 4 of KRAS and NRAS gene and for BRAF the V600E mutation were examined. 


\section{Statistical Analysis}

In the present subgroup analysis of patients with RAS and BRAF-mutant tumours, response rates and ORR (objective response rate) were analysed using two-sided Fisher's exact test. PFS (progression free survival) and OS (overall survival) were evaluated according to the Kaplan Meier method (including median time and $95 \%$ confidence intervals [CIs] for the median). Differences between treatment arms were assessed using the log rank test, and the Cox proportional hazard method was used to calculate the hazard ratio (including 95\% confidence interval). The ORR was evaluated according to the Response Evaluation Criteria in Solid Tumors (RECIST) ver. 1.1. PFS was defined as the duration of survival from the start of chemotherapy to the date of recurrence or death from any cause, whichever occurred first. Patients with no recurrence until the cut-off date were regarded as censored on the last date when no recurrence had been proven by imaging. The disease-progression date was retrospectively re-analysed by the investigator, and was defined as the date on which progression was first detected using a computed tomography (CT) or fluoro-deoxyglucose positron emission tomography (FDG-PET) scan. If treatments were discontinued before or continued after diseaseprogression due to adverse events or the patient's request, they were censored at the time of the last radiological examination. OS was defined as survival from the start of chemotherapy to death from any cause. For patients who were lost to follow-up, data were censored on the date when the patient was last known to be alive.

\section{RESULTS}

The baseline characteristics of the patients are shown in Table 1. Their median age was 63 years (range, 23-86 years). 188 patients $(62.0 \%)$ were men and 115 patients $(38.0 \%)$ were women. Almost all of the subjects had a good performance status. 194 patients $(64.1 \%)$ had colon cancer and 109 (35.9\%) had rectal cancer, including right-sided colon cancer (RCC) in 72 patients $(22.7 \%)$ and left-sided colorectal cancer (LCRC) in 227 patients (74.9\%). Tumour location could not be determined in 4 patients. RCC was defined as a tumour arising from the cecum to the transverse colon, excluding the appendix, while LCRC was defined as a tumour arising from the descending colon to the rectum. The baseline characteristics according to the tumour location are shown in Table 2. There was not statistically difference in baseline characteristics between the tumor location subgroups. A higher proportion of patients with right-sided tumors were BRAF mutant (22.2 vs 2.7\%) (Table 2).

The frequencies of study population $(n=303)$ were as follows: 288 KRAS, 149 NRAS were investigated, 15 patients mutation analysis were not investigated. In total, the final RAS-mutant population consisted of 128 patients (44.4\%). 104 patients were KRAS mutant, 24 patient were NRAS mutant. 11 patients had both RAS and BRAF mutations. 22 patients had BRAF mutation. 117 only RAS mutant patients were treated with beva combination. Of those 149 (51.7\%) RAS wild patients, at first line regimen 104 patient were treated with FOLFIRI or FOLFOX plus anti-EGFR and 45 with FOLFIRI or FOLFOX plus beva.

BRAF mutation was detected in $22(12.2 \%)$ of 180 patients who underwent BRAF mutation test. 11 Both of RAS and BRAF mutation were identified together. 22 BRAF mutation patients, of these, 7 received treatment with FOLFIRI-FOLFOX plus anti-EGFR and 15 with FOLFIRI-FOLFOX plus beva. No major differences in baseline characteristics were detected between both treatments arms regarding both, RAS- and BRAF-mutant populations (Table 1).

The median follow-up period for all eligible patients was 22.8 (19.1-26.4) months, and 197 patients $(65.0 \%)$ died by the cut-off date, $106(35.0 \%)$ patients still alive.

Median follow-up times were 26.0 months for the RAS wild subgroup. The overall event rates for RAS wild patients were $72.5 \%$ for PFS and $61.7 \%$ for OS. In this group, OS was 26.0 months; there was no statistically significant difference between taking anti-EGFR or Beva in addition to chemotherapy $(\mathrm{p}=0.418 \mathrm{HR}=0.75)$ (Respectively, Median OS; 29.3 vs 21.7 months). Median PFS was 11.5 months; there was significantly difference between taking anti-EGFR or Beva in addition to chemotherapy, $(\log$ rank $\mathrm{p}=0.007 \mathrm{HR}=0.59)(\mathrm{Re}-$ spectively Median PFS; 14.5 vs 8.7 months) (Figure 1). 
International Journal of Hematology and Oncology

\begin{tabular}{|c|c|c|c|c|c|c|c|c|c|}
\hline & \multicolumn{3}{|c|}{ RAS wild ( $n=149$ ) } & \multicolumn{3}{|c|}{ RAS mutant ( $n=117$ ) } & \multicolumn{3}{|c|}{ BRAF mutant $(n=22)$} \\
\hline & $\begin{array}{l}\text { Folfox-folfiri- } \\
\text { antiEGFR } \\
(n=104)\end{array}$ & $\begin{array}{l}\text { Folfox- } \\
\text { folfiri-beva } \\
(n=45)\end{array}$ & $p$ & $\begin{array}{l}\text { Folfox-beva } \\
(n=57)\end{array}$ & $\begin{array}{l}\text { Folfiri-beva } \\
(n=60)\end{array}$ & $p$ & $\begin{array}{l}\text { Folfox-folfiri- } \\
\text { antiEGFR } \\
(n=7)\end{array}$ & $\begin{array}{l}\text { Folfox-folfiri- } \\
\text { beva } \\
(n=15)\end{array}$ & $p$ \\
\hline & n (69.8\%) & n (30.2\%) & & n (48.7\%) & n (51.3\%) & & n (31.8\%) & n (68.2\%) & \\
\hline Sex & & & 0.79 & & & 0.56 & & & 0.34 \\
\hline Male & $66(51.9)$ & 31 (68.9) & & $33(57.9)$ & $34(56.6)$ & & $3(42.9)$ & $11(73.3)$ & \\
\hline Female & $38(36.5)$ & $14(31.1)$ & & $24(42.1)$ & $26(43.4)$ & & $4(67.1)$ & $4(26.7)$ & \\
\hline Median age: 60 y & & & 0.85 & & & 0.16 & & & 0.34 \\
\hline Age $\leq 65$ & $68(65.4)$ & 27 (60.0) & & $34(59.6)$ & 29 (48.3) & & $3(42.8)$ & $11(73.3)$ & \\
\hline Age $>65$ & $36(34.6)$ & $18(40.0)$ & & $23(40.4)$ & $31(51.7)$ & & $4(57.2)$ & $4(26.7)$ & \\
\hline ECOG, n (\%) & & & 0.62 & & & 0.11 & & & 0.87 \\
\hline 0 & $33(31.7)$ & $9(20.0)$ & & $14(24.6)$ & $13(21.6)$ & & 2 (28.5) & $4(26.7)$ & \\
\hline 1 & $63(60.5)$ & $28(62.3)$ & & $37(61.6)$ & $37(64.9)$ & & $3(43.0)$ & $8(53.3)$ & \\
\hline 2 & $8(7.6)$ & $8(17.7)$ & & $6(10.5)$ & $10(16.6)$ & & $2(28.5)$ & $3(20.0)$ & \\
\hline Right Colon & $18(17.3)$ & $9(20.0)$ & 0.64 & 13(22.8) & $15(25.0)$ & 0.03 & $5(11.4)$ & $11(73.3)$ & 0.65 \\
\hline Left Colon & $85(81.7)$ & 33 (73.3) & & $44(77.2)$ & 45 (75.0) & & $2(28.6)$ & $4(26.7)$ & \\
\hline Unknown & $1(0.9)$ & $3(6.7)$ & & & & & & & \\
\hline 1 metastasis & $22(21.2)$ & $8(17.8)$ & 0.60 & $10(17.5)$ & $9(15.0)$ & 0.47 & $1(14.3)$ & $3(20.0)$ & 0.22 \\
\hline$>2$ metastasis & $57(54.8)$ & $30(6.7)$ & & $38(66.7)$ & $41(68.3)$ & & $4(57.1)$ & $7(46.7)$ & \\
\hline Periton metastasis & $25(24.0)$ & $7(15.6)$ & & $9(15.8)$ & $10(16.7)$ & & $2(28.6)$ & $5(33.3)$ & \\
\hline Metastasectomy (+) & $31(29.8)$ & $11(24.4)$ & 0.55 & $13(22.8)$ & $11(18.3)$ & 0.10 & $1(14.3)$ & 5 (33.3) & 0.61 \\
\hline Metastasectomy (-) & $73(70.2)$ & $34(75.6)$ & & $44(77.2)$ & $49(81.7)$ & & $6(85.7)$ & $10(66.6)$ & \\
\hline Primer Surgery (+) & $76(73.1)$ & $29(64.4)$ & 0.50 & 47 (82.5) & $34(56.7)$ & 0.001 & $4(57.2)$ & $9(60.0)$ & 0.62 \\
\hline Primer Surgery (-) & $28(26.9)$ & $16(35.6)$ & & $10(17.5)$ & 26 (43.3) & & $3(42.8)$ & $6(40.0)$ & \\
\hline Adjuvan KT, n (\%) & & & 0.01 & & & 0.01 & & & 0.63 \\
\hline Yes & $46(44.2)$ & $18(40.0)$ & & $28(49.1)$ & $21(35.0)$ & & $3(42.8)$ & $4(26.7)$ & \\
\hline No & $58(55.8)$ & $27(60.0)$ & & 29(50.9) & $39(65.0)$ & 0.01 & $4(57.2)$ & 11(73.3) & \\
\hline Radio therapy, n (\%) & & & 0.01 & & & 0.24 & & & 0.31 \\
\hline Yes & $10(9.6)$ & $4(8.8)$ & & $3(5.2)$ & $2(3.3)$ & & $1(14.3)$ & $0(0)$ & \\
\hline No & 94 (90.4) & $41(91.2)$ & & 54 (84.8) & 58 (96.7) & & $6(85.7)$ & $15(100)$ & \\
\hline
\end{tabular}

Median follow-up times were 23.5 months for the RAS mutant subgroup. The overall event rates for RAS mutant patients were $70.4 \%$ for PFS and $63.5 \%$ for OS. In this group, OS was 23.5 months; there was not statistically significant difference between taking FOLFIRI-beva or FOLFOX-beva $(\mathrm{p}=0.347)$ (Respectively Median OS; 24.7 and 21.3 months.) Median PFS was 10.0 months, and similar in the patients treated with FOLFIRI and FOLFOX regimens $(p=0.622)$ (Respectively median PFS; 12.0 and 9.0 months.)

Median follow-up times were 23.5 months for the RAS and 14.2 months for the BRAF-mutant subgroup, respectively. The overall event rates for RAS mutant and BRAF mutant patients were $70.4 \%$ versus $90.9 \%$ for PFS and $63.5 \%$ versus $81.8 \%$ for OS. Within the BRAF-mutant subgroup, tumour response, PFS and OS were not significantly different in both treatment arms (see Tables 3 and 4). Median PFS and median OS times were markedly shorter in the BRAF mutant when compared to the RAS mutant and RAS wild population. Median treatment duration was in trend shorter in the beva than in the anti-EGFR arm (13.8 months versus 26.2 months), but due to low patient numbers, this difference did not reach statistical significance. In the patients with BRAF mutant tumors, median PFS was shorter with FOLFOX-FOLFIRI plus anti-EGFR than CT-Beva arm but this differ- 


\begin{tabular}{|c|c|c|c|}
\hline & Right Colon & Left Colon & $\mathbf{p}$ \\
\hline Sex & & & 0.30 \\
\hline Male & $48(66.7 \%)$ & $136(59.9 \%)$ & \\
\hline Female & 24 (33.3\%) & $91(40.1 \%)$ & \\
\hline Median age: 60 & & & 0.25 \\
\hline Age $\leq 65$ & 39 (54.2\%) & 140 (61.7\%) & \\
\hline Age $>65$ & $33(45.8 \%)$ & 87 (38.3\%) & \\
\hline ECOG & & & 0.15 \\
\hline 0 & 21 (29.2\%) & $56(24.7 \%)$ & \\
\hline 1 & 38 (52.8\%) & $146(64.3 \%)$ & \\
\hline 2 & $13(18.1 \%)$ & $25(11 \%)$ & \\
\hline 1 metastasis & $12(16.7 \%)$ & 43 (18.9\%) & 0.63 \\
\hline$>2$ metastasis & $42(58.3 \%)$ & $139(61.2 \%)$ & \\
\hline Periton metastasis & $18(25 \%)$ & 45 (19.8\%) & \\
\hline Metastasectomy (+) & 19 (26.4\%) & 59 (26\%) & 0.94 \\
\hline Metastasectomy (-) & $53(73.6 \%)$ & $168(74 \%)$ & \\
\hline Primer Surgery (+) & $52(72.2 \%)$ & 157 (69.2\%) & 0.24 \\
\hline Primer Surgery (-) & 20 (27.8\%) & 70 (30.8\%) & \\
\hline Adjuvan KT, n (\%) & & & 0.38 \\
\hline Yes & 39 (54.2\%) & $91(40.1 \%)$ & \\
\hline No & $33(45.8 \%)$ & 136 (59.9\%) & \\
\hline Radiotherapy;n (\%) & & & 0.26 \\
\hline Yes & $0(0 \%)$ & $21(9.3 \%)$ & \\
\hline No & 72 (100\%) & 206 (90.7\%) & \\
\hline First-line AntiEGFR usage & 23 (31.9\%) & 87 (39\%) & \\
\hline antiEGFR-PFS & $14.7(9.6-19.8)$ & $12.5(8.2-16.8)$ & 0.09 \\
\hline antiEGFR-OS & Not reached & $24.3(14.4-34.1)$ & \\
\hline First-line Bevacizumab usage & 49 (68.1\%) & $136(61 \%)$ & \\
\hline Bevacizumab-PFS & $9.6(6.7-12.4)$ & $9.0(6.4-11.5)$ & 0.09 \\
\hline Bevacizumab-OS & $16.6(11.6-21.5)$ & $22.8(19.3-26.2)$ & 0.77 \\
\hline RAS Wild & $27(37.5 \%)$ & $118(51.9 \%)$ & 0.29 \\
\hline RAS Mutant & 28 (38.9\%) & 89 (39.2\%) & 0.29 \\
\hline BRAF Mutant & $16(22.2 \%)$ & $6(2.7 \%)$ & 0.01 \\
\hline PFS & $10.4(7.8-12.9)$ & $10.0(7.79-12.2)$ & 0.13 \\
\hline OS & $21.5(12.0-30.9)$ & $23.1(18.7-27.4)$ & 0.43 \\
\hline
\end{tabular}

ence had not reached statistically difference (3.5 versus 6.0 months, log-rank test $\mathrm{p}=0.592 \mathrm{HR}=$ 0.76). And also; median OS times were similar in two treatment arms in the patients with BRAF mutant tumors (Median OS 26.2 versus 13.8 months, log-rank test $\mathrm{p}=0.113, \mathrm{HR}=0.40$ ) (Figure 2).

Overall response rate (ORR) in the BRAF-mutant patient population was reached in $28.5 \%(2 / 7)$ in the anti-EGFR arm and $60.0 \%(9 / 15)$ in the beva arm (two-sided Fisher's exact test $\mathrm{p}=0.314$ ). ORR in the RAS-mutant patient population was reached $65.0 \%(n=37)$ in the FOLFIRİ-bev arm and $45.0 \%$ $(n=27)$ in the FOLFOX-beva arm (two-sided Fisher's exact test $\mathrm{p}=0.54$ ) (Table 3 ).

According to tumor sidedness, there was no significant between two groups (Median PFS; 10.4 vs 10.0 months $(\log$ rank test $\mathrm{p}=0.136)$, median OS: 21.5 vs 23.1 months ( $\log \operatorname{rank} \mathrm{p}=0.436)$, in the patients with right and left sided primary tumours, respectively) (Table 2). 


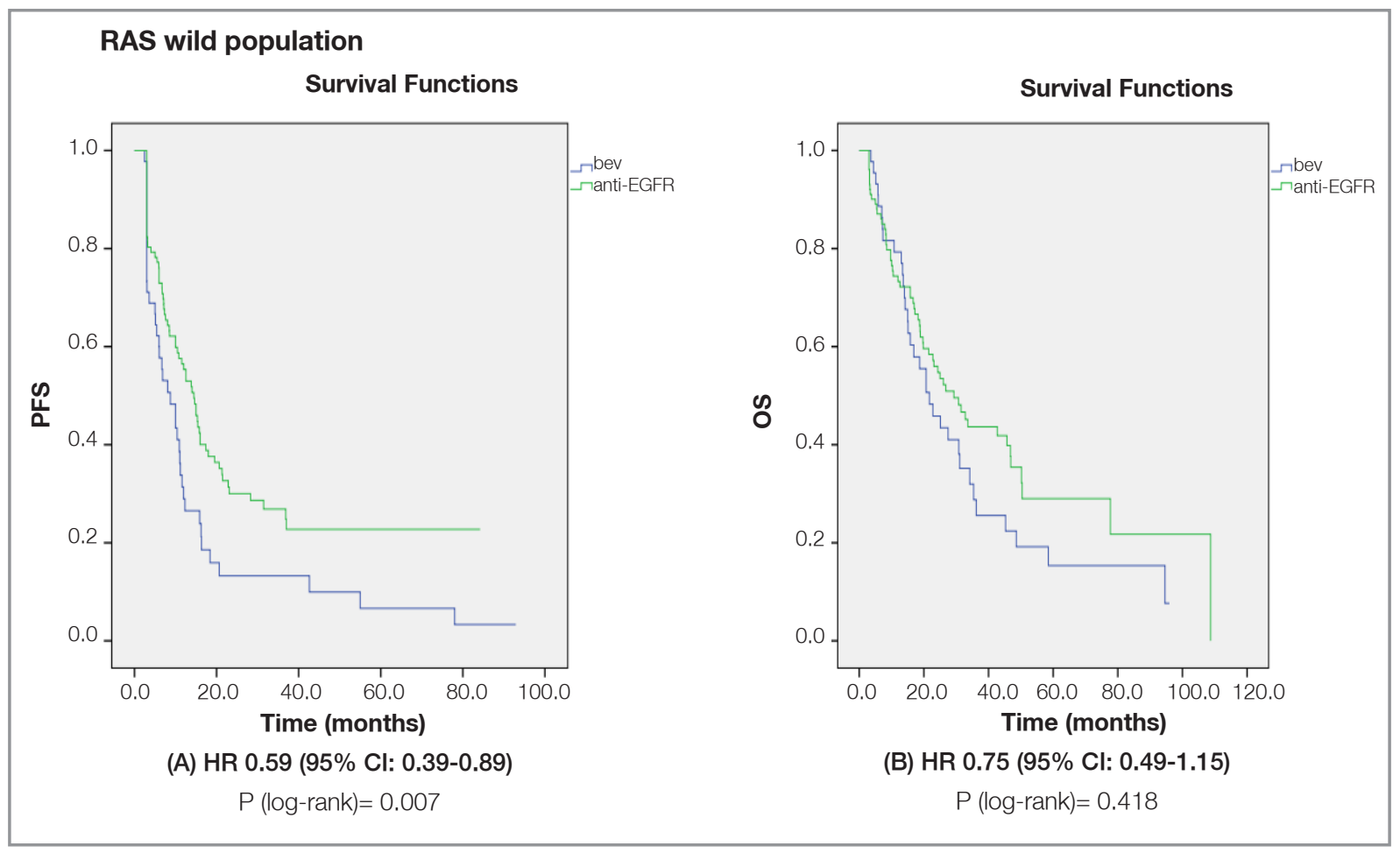

Figure 1. PFS and OS survival curves (Kaplan Meier estimates) $\mathrm{RAS}=$ rat sarcoma; bev= bevacuzimab; antiEGFR= cetuximab or panitumumab; OS= overall survival; PFS= progression-free survival; $\mathrm{Cl}=$ confidence interval; $\mathrm{HR}=$ hazard ratio

\section{DISCUSSON}

This retrospective trial was conducted to investigate survival and treatment results in the patients with mCRC according to RAS and BRAF mutational status. According to our knowledge, there is strong evidence that anti-EGFR agents are not active in patients with RAS-mutant tumours. A detrimental effect of anti-EGFR agents has, however, only been observed when oxaliplatin-containing chemotherapies were used. ${ }^{13,14}$ Optimal treatment of BRAF-mutant mCRC still remains an open question. ${ }^{15,16}$

\begin{tabular}{|c|c|c|c|c|c|c|c|c|c|}
\hline & \multicolumn{3}{|c|}{ RAS wild (n= 149) } & \multicolumn{3}{|c|}{ RAS mutant $(n=117)$} & \multicolumn{3}{|c|}{ BRAF mutant $(n=22)$} \\
\hline & $\begin{array}{l}\text { Folfox-folfiri- } \\
\text { antiEGFR } \\
(n=104)\end{array}$ & $\begin{array}{l}\text { Folfox- } \\
\text { folfiri-beva } \\
(n=45)\end{array}$ & $p$ & $\begin{array}{l}\text { Folfox-beva } \\
(n=57)\end{array}$ & $\begin{array}{l}\text { Folfiri-beva } \\
(n=60)\end{array}$ & $p$ & $\begin{array}{l}\text { Folfox-folfiri- } \\
\text { antiEGFR } \\
(n=7)\end{array}$ & $\begin{array}{l}\text { Folfox-folfiri- } \\
\text { beva } \\
(n=15)\end{array}$ & \\
\hline \multirow[t]{2}{*}{ Complete Response } & 24 & 5 & & 6 & 10 & & 1 & 2 & \\
\hline & (29.4\%) & (11.1\%) & & (10.7\%) & (16.9) & & (14.3\%) & (13.3\%) & \\
\hline \multirow[t]{2}{*}{ Partial Response } & 37 & 14 & & 31 & 17 & & 1 & 7 & \\
\hline & (38.5\%) & $(31.1 \%)$ & & (55.4\%) & $(28.8)$ & & $(14.3 \%)$ & $(46.7 \%)$ & \\
\hline \multirow[t]{2}{*}{ Stable Disease } & 18 & 9 & & 9 & 12 & & 1 & 3 & \\
\hline & $(11.5 \%)$ & (20.0\%) & & $(14.3 \%)$ & $(18.6)$ & & $(14.3 \%)$ & (20.0\%) & \\
\hline \multirow{2}{*}{ Progressive Disease } & 25 & 17 & & 11 & 21 & & 4 & 3 & \\
\hline & (20.5\%) & $(37.8 \%)$ & & (19.6\%) & (35.6) & & (57.1\%) & $(20.0 \%)$ & \\
\hline \multirow[t]{2}{*}{ ORR } & 61 & 19 & 0.06 & 37 & 27 & 0.54 & 2 & 9 & 0.31 \\
\hline & (58.7\%) & (42.2\%) & & (65.0\%) & $(45.0)$ & 0.54 & (28.6\%) & (60.0\%) & \\
\hline
\end{tabular}






Figure 2. PFS and OS survival curves (Kaplan Meier estimates) $\mathrm{BRAF}=$ proto-oncogene $\mathrm{B}-\mathrm{Raf} ;$ bev= bevacuzimab; antiEGFR= cetuximab or panitumumab; OS= overall survival; $\mathrm{PFS}=$ progression-free survival; $\mathrm{Cl}=$ confidence interval; $\mathrm{HR}=$ hazard ratio

We considered that PFS, which is compared, to time to treatment failure (TTF) would be a more appropriate endpoint to evaluate the biological activity of the tumour and drug resistance. OS was the strictest endpoint but would be determined by not only the first-line treatment but also by secondline and subsequent treatments. The difference in OS may be a result of different subsequent chemotherapy plus biological treatments in patients who have RAS or BRAF mutant, and different chemo- therapy plus anti-EGFR therapy after the first-line treatment in patients who have KRAS or RAS wild-type tumors. For this reason, we assessed the relationship between clinic-pathologic factors including RAS and BRAF tumor mutation status and PFS.

In this trial, we found that the patients with a RAS or BRAF mutation had a similar ORR like patients with tumours that did not carry these mutations;

\begin{tabular}{|c|c|c|c|c|c|c|c|c|c|}
\hline & \multicolumn{3}{|c|}{ RAS wild ( $n=149$ ) } & \multicolumn{3}{|c|}{ RAS mutant $(n=117)$} & \multicolumn{3}{|c|}{ BRAF mutant $(n=22)$} \\
\hline & $\begin{array}{l}\text { Folfox-folfiri- } \\
\text { antiEGFR } \\
(n=104)\end{array}$ & $\begin{array}{l}\text { Folfox- } \\
\text { folfiri-beva } \\
(n=45)\end{array}$ & $\mathrm{p}$ & $\begin{array}{l}\text { Folfox-beva } \\
(n=57)\end{array}$ & $\begin{array}{l}\text { Folfiri-beva } \\
(n=60)\end{array}$ & $p$ & $\begin{array}{l}\text { Folfox-folfiri- } \\
\text { antiEGFR } \\
(n=7)\end{array}$ & $\begin{array}{l}\text { Folfox-folfiri- } \\
\text { beva } \\
(n=15)\end{array}$ & $p$ \\
\hline $\begin{array}{l}\text { Median PFS } \\
\text { (months) }\end{array}$ & $\begin{array}{l}14.5 \\
(11.2-17.7)\end{array}$ & $\begin{array}{l}8.7 \\
(4.6-12.8)\end{array}$ & 0.007 & $\begin{array}{l}10.0 \\
(6.8-13.1)\end{array}$ & $\begin{array}{l}11.6 \\
(6.4-16.8)\end{array}$ & 0.62 & $\begin{array}{l}3.5 \\
(2.2-4.7)\end{array}$ & $\begin{array}{l}6 \\
(4.8-7.1)\end{array}$ & 0.59 \\
\hline $\begin{array}{l}\text { Median OS } \\
\text { (months) }\end{array}$ & $\begin{array}{l}29.3 \\
(20.3-38.2)\end{array}$ & $\begin{array}{l}21.7 \\
(13.6-29.7)\end{array}$ & 0.41 & $\begin{array}{l}23.5 \\
(16.1-30.8)\end{array}$ & $\begin{array}{l}22.8 \\
(14.5-31.0)\end{array}$ & 0.34 & $\begin{array}{l}26.2 \\
(1.8-50.5)\end{array}$ & $\begin{array}{l}13.8 \\
(7.3-20.2)\end{array}$ & 0.11 \\
\hline
\end{tabular}


it was attributed to similar rates of chemotherapy regimen and biological agent usage ever in the patients with RAS mutations.

Data from preclinical research has indicated that changes in the EGFR signalling pathway might be related to the efficacy of anti-VEGF therapy. ${ }^{17}$ Post-analysis of the AVF2107g trial revealed that adding Beva to cytotoxic chemotherapy was useful regardless of KRAS exon 2-mutation status although, KRAS exon 2 mutations are not predictive markers of Beva treatment. ${ }^{18}$ Nonetheless, we found that the ORR, PFS, and OS similar between in the patients with KRAS wild-type and mutant tumors (ORR, $53.6 \%$ vs. $55.1 \%$; PFS, 11.5 months vs. 10.0 months; OS, 26.0 months vs. 23.5 months). These findings are consistent with other trials comparing clinical outcomes between patients with KRAS exon 2 wild-type and mutant tumors. ${ }^{19-21}$ In our trial, RAS mutation seems to be a predictive marker for anti-EGFR treatment but not a prognostic factor. Although there were numerical survival differences between KRAS wild and mutated patients, this difference was not reached statistical significance. (Median PFS: $14.5 \mathrm{vs} 10.0 \mathrm{log}$ rank, $\mathrm{p}=0.092$, OS: 29.3 vs $23.5 \log$ rank $\mathrm{p}=0.245$ )

Similar to previous reports, in the current study, BRAF mutation was a strong indicator of poor prognosis even in the presence of RAS wild and anti-EGFR treatment. In the RAS wild population the patients with BRAF-mutant tumours had a poor prognosis and significantly shorter PFS (6.0 vs 11.5 months) and OS (14.2 vs 26.0 months). In the patients with both RAS and BRAF mutated tumours compared to RAS mutant but BRAF wild type tumours, had shorter survival times (median PFS 6.0 vs 10.0 months and OS 14.2 vs 23.5 months). There were similar results in the literature. Cremolini et al. reported a PFS of 5.5 months and an OS of 10.7 months for BRAF-mutant patients treated with FOLFIRI plus bevacizumab. ${ }^{22}$ Similarly, BRAF-mutant patients receiving FOLFIRI plus cetuximab in the CRYSTAL study had a median PFS of 8.0 months and a median OS of 14.1 months. ${ }^{23}$ In FIRE-3, BRAF mutant patients had worst outcome regardless of biological agent (Median PFS for cetuximab and bevacuzimab 6.6 vs 6.6 months, median OS 12.2 vs 13.7 months). ${ }^{1}$ In the current study, our patients with BRAF mutation had simi- lar outcomes with cetuximab and bevacizumab. It was attributed to small sample size of BRAF mutant tumors. However, in the FIRE3 study, with FOLFIRI plus cetuximab, early tumor shrinkage was observed in the half of patients with BRAF mutation. In the future, experimental analyses of molecular subtypes and gene expression profiles of tumour specimens can be explain to different behaviour and treatment responses of BRAF mutant tumors. There was growing evidence in the literature about the fact of all BRAF-mutant tumours have not a same biological behaviour. Barras et al. ${ }^{24}$ were built a gene expression dataset of 218 BRAF V600E mutant (BM) colorectal cancer patients from different clinical trials. According to gene expression profiles, BRAF mutant colorectal cancer was segregated into two different subtypes BM1 and BM2. BM1 subtype was highly active in $\mathrm{KRAS} / \mathrm{mTOR} / \mathrm{AKT} / 4 \mathrm{EBP} 1$ signalling and in genes associated with macrophage infiltration and EMT (epithelial-to-mesenchymal transition) and the BM2 subtype in cell cycle and cycle checkpoint associated genes. The authors suggested that BM1 patients could have benefit from this antiEGFR and BRAF inhibition. It has been reported that cells with activated EMT do not respond to cetuximab. ${ }^{25}$ But not only BRAF subtypes, there were many conflicting factors of prognosis, such as MSI status and molecular subtypes of CRC. ${ }^{26}$

We also investigated that the prognostic and predictictive effects of tumor sidedness. Similar to literature, BRAF mutation was higher in the right sided primary and despite of active chemotherapy regimen and biological agent usage, right sided primary tumors have worse survival. However, due to low percentage of right sided primary, survival difference between two groups was not reached statistically significance.

In the RAS-mutant cohort of 117 patients who treated with chemotherapy plus bevacizumab PFS and OS were similar with both FOLFOX and FOLFIRI (median PFS 11.6 vs 10.0, median OS 22.8 vs 23.5 months). According to updated results of CRYSTAL trial, in the RAS mutant population, median PFS was 7.4 an OS was 16.4 months with FOLFIRI plus cetuximab. ${ }^{27}$ Similarly, in the TRIBE trial, median PFS of 9.5 and median OS of 23.9 months were shown for RAS-mutant patients 
receiving FOLFIRI plus bevacizumab. ${ }^{22}$ Our data has retrospective nature, however survival times were in concordance with randomised prospective trials.

It was demonstrated that all ras mutations and braf mutation predicted poor prognosis and poor treatment response to $\mathrm{CT}$ and an-EGFR treatment. ${ }^{1,3,22,28}$ Our trial showed that $\mathrm{mCRC}$ patients with BRAF mutation (PFS 6 months vs 10 months, OS 13.8 vs 23.5 months) had a poorer response to combination chemotherapy with Bmab than the patients, who had none of these mutations, but RAS mutation had similar response and survey compared to RAS wild patients.

Our study has several limitations. Firstly, this was retrospective cohort study. Secondly, due to the rare incidence of BRAF mutation in CRC, we could evaluate only small number patients with these mutations. However, we presented our clinical data and treatment results from 3 centres, there was no financial support and commercial effect on our results, it reflects real life, it can give neutral and interest-free results.

In summary, we concluded that, RAS mutant patients can be achieved similar survival rates compared to RAS wild type tumour with early usage of active chemotherapy regimen with bevacizumab, this success does not seem to use of second line treatment regimen. Despite of retrospective nature of our study, survival times were concordant with randomised trials both of RAS wild and mutant populations. Moreover, BRAF mutation has most detrimental effect on survival times in mCRC regardless of treatment regimens. Similar to previous data, right-sided primary was associated with higher BRAF mutation rate and worse survival regardless of first line treatment regimen. The patients with BRAF mutant tumor or right-sided primary need to different targeted therapies and more aggressive chemotherapy regimens. Moreover; some patients who had BRAF mutated and/or right-sided primary tumors had clinical benefit from anti-EGFR agents, in the near future, molecular characterisation of CRC can identify these patients.

\section{REFERENCES}

1. Stintzing S, Modest DP, Rossius L, et al. Impact of BRAF and RAS mutations on first-line efficacy of FOLFIRI plus cetuximab versus FOLFIRI plus bevacizumab: analysis of the FIRE-3 (AIO KRK-0306) study. Eur J Cancer 79: 50-60, 2017.

2. Loupakis F, Cremolini C, Masi G, et al. Initial therapy with FOLFOXIRI and bevacizumab for metastatic colorectal cancer. N Engl J Med 371: 1609-1618, 2014.

3. Venook AP, Niedzwiecki D, Lenz HJ, et al. CALGB/SWOG 80405: Effect of first-line chemotherapy combined with cetuximab or bevacizumab on overall survival in patients with KRAS wild-type advanced or metastatic colorectal cancer. JAMA 317: 2392-2401, 2017.

4. Sorich MJ, Wiese MD, Rowland A, et al. Extended RAS mutations and anti-EGFR monoclonal antibody survival benefit in metastatic colorectal cancer: a meta-analysis of randomized, controlled trials. Ann Oncol 26: 13-21, 2015.

5. De Roock W, De Vriendt V, Normanno N, et al. KRAS, BRAF, PIK3CA, and PTEN mutations: implications for targeted therapies in metastatic colorectal cancer. Lancet Oncol 12: 594603, 2011.

6. Network NCC. NCCN guidelines colon cancer version 4.2020. 2020 https://www.nccn.org/professionals/physician_gls/pdf/colon.pdf

7. Van Cutsem E, Cervantes A, Adam R, et al. ESMO consensus guidelines for the management of patients with metastatic colorectal cancer. Ann Oncol 27: 1386-1422.

8. Guinney J, Dienstmann R, Wang $X$, et al. The consensus molecular subtypes of colorectal cancer. Nat Med 21: 13501356, 2015.

9. Kim SE, Paik HY, Yoon H et al. Sex- and gender-specific disparities in colorectal cancer risk. World J Gastroenterol 21: 5167-5175, 2015.

10. Yamauchi M, Morikawa T, Kuchiba A, et al. Assessment of colorectal cancer molecular features along bowel subsites challenges the conception of distinct dichotomy of proximal versus distal colorectum. Gut 61: 847-854, 2012.

11. Loupakis F, Yang D, Yau L, et al. Primary tumor location as a prognostic factor in metastatic colorectal cancer. J Natl Cancer Inst 107: 1-9, 2015.

12. Laurent-Puig P, Grisoni ML, Heinemann V, et al. MiR-31-3p is a predictive biomarker of cetuximab response in the FIRE3 trial. Ann Oncol 2016; 27 (suppl 6): Abstract 4570 ESMO 2016 Denmark Copenhagen.

13. Douillard JY, Oliner KS, Siena S, et al. K-ras mutations and benefit from cetuximab in advanced colorectal cancer. N Engl J Med 369: 1023-1034, 2013.

14. Bokemeyer $\mathrm{C}$, Kohne $\mathrm{CH}$, Ciardiello F, et al. FOLFOX4 plus cetuximab treatment and RAS mutations in colorectal cancer. Eur J Cancer 51: 1243-1252, 2015. 
15. Di Nicolantonio F, Martini M, Molinari F, et al. Wild-type BRAF is required for response to panitumumab or cetuximab in metastatic colorectal cancer. J Clin Oncol 26: 5705-5712, 2008.

16. Rowland A, Dias MM, Wiese MD, et al. Meta-analysis of BRAF mutation as a predictive biomarker of benefit from antiEGFR monoclonal antibody therapy for RAS wild-type metastatic colorectal cancer. Br J Cancer 112: 1888-1894, 2015.

17. Ince WL, Jubb AM, Holden SN, et al. Association of k-ras, b-raf, and p53 Status With the Treatment Effect of bevacizumab. J Natl Cancer Inst 97: 981-989, 2005.

18. Hurwitz HI, Yi J, Ince W, et al. The clinical benefit of bevacizumab in metastatic colorectal cancer is independent of K-ras mutation status: analysis of a phase III study of bevacizumab with chemotherapy in previously untreated metastatic colorectal cancer. Oncologist 14: 22-28, 2009.

19. Hecht JR, Mitchell E, Chidiac T, et al. A randomized phase IIIB trial of chemotherapy, bevacizumab, and panitumumab compared with chemotherapy and bevacizumab alone for metastatic colorectal cancer. J Clin Oncol 27: 672-680, 2009.

20. Price TJ, Hardingham JE, Lee CK, et al. Impact of KRAS and BRAF Gene Mutation Status on Outcomes From the Phase III AGITG MAX Trial of Capecitabine Alone or in Combination With Bevacizumab and Mitomycin in Advanced Colorectal Cancer. J Clin Oncol 29: 2675-2682, 2011.

21. Díaz-Rubio E, Gómez-España A, Massutí B, et al. Role of Kras status in patients with metastatic colorectal cancer receiving first-line chemotherapy plus bevacizumab: a TTD group cooperative study. PLoS One 7: e47345, 2012.

22. Cremolini C, Loupakis F, Antoniotti C, et al. FOLFOXIRI plus bevacizumab versus FOLFIRI plus bevacizumab as first-line treatment of patients with metastatic colorectal cancer: updated overall survival and molecular subgroup analyses of the open-label, phase 3 TRIBE study. Lancet Oncol 16: 1306$1315,2015$.

23. Van Cutsem E, Kohne $\mathrm{CH}$, Lang I, et al. Cetuximab plus irinotecan, fluorouracil, and leucovorin as first-line treatment for metastatic colorectal cancer: updated analysis of overall survival according to tumor KRAS and BRAF mutation status. J Clin Oncol 29: 2011-2019, 2011.

24. Barras D, Missiaglia E, Wirapati $P$, et al. BRAF V600E mutant colorectal cancer subtypes based on gene expression. Clin Cancer Res 23: 104-115, 2017.
25. Oliveras-Ferraros C, Vazquez-Martin A, Cufi S, et al. Stem cell property epithelial-tomesenchymal transition is a core transcriptional network for predicting cetuximab (Erbitux) efficacy in KRAS wild-type tumor cells. J Cell Biochem 112: 10-29, 2011.

26. Le DT, Uram JN,Wang H, et al. PD-1 blockade in tumors with mismatch-repair deficiency. N Engl J Med 372: 2509-2520, 2015.

27. Van Cutsem E, Lenz HJ, Kohne CH, et al. Fluorouracil, leucovorin, and irinotecan plus cetuximab treatment and RAS mutations in colorectal cancer. J Clin Oncol 33: 692-700, 2015.

28. Rivera F, Karthaus $M$, Hecht JR, et al. Final analysis of the randomised PEAK trial: overall survival and tumour responses during first-line treatment with mFOLFOX6 plus either panitumumab or bevacizumab in patients with metastatic colorectal carcinoma. Int J Colorectal Dis 32: 1179-1190, 2017

\section{Correspondence: \\ Dr. Kadir ESER}

Mersin Egitim ve Arastirma Hastanesi

Tibbi Onkoloji Bolumu

Korukent Mahallesi 96015 Sokak

Mersin Entegre Saglik Kampüsü

33240 Toroslar, MERSIN / TURKEY

Tel: (+90-505) 9125520

e-mail: drkadireser@gmail.com

\section{ORCIDs:}

Kadir Eser

0000-0001-8666-6117

Emel Sezer

0000-0001-9881-3533

Banu Oztürk

0000-0003-0290-8787

Arif Hakan Onder

$0000-0002-0121-5228$

Vehbi Erçolak

0000-0003-1014-1694

Zeynep Oruc

0000-0002-7931-2941

Ali Inal

0000-0001-9510-9858 